\title{
PRESENTACIÓN
}

\section{Enfermedades raras del corazón}

\author{
Rare heart diseases
}

Darío Echeverri1,2*

${ }^{1}$ Servicio de Cardiología, Fundación Cardioinfantil, Instituto de Cardiología; ${ }^{2}$ Editor Jefe, Revista Colombiana de Cardiología. Bogotá, Colombia

En nombre de la Sociedad Colombiana de Cardiología y Cirugía Cardiovascular y de su órgano oficinal, la Revista Colombiana de Cardiología, queremos dar el reconocimiento a la Dra. María Juliana Rodríguez y al Dr. José Ramón González-Juanatey como editores del actual suplemento con el título de Enfermedades raras del corazón, y a todos los distinguidos autores de los diferentes artículos que lo conforman por el gran esfuerzo en el logro de este número extraordinario con los diferentes tópicos tratados con gran solvencia y nivel científico.

Infortunadamente, es muy difícil conocer con certeza la prevalencia o la incidencia específica de cualquiera de las enfermedades raras. La definición depende del país o de la región. La Comisión Europea de Salud Pública las define como aquellas que se presentan en menos de una de cada 2000 personas. Un cierto porcentaje de los casos no se notifica, otro no se diagnostica y otro se diagnostica erróneamente. Parece haber un consenso cada vez mayor en que existen alrededor de 7000 enfermedades raras. Las enfermedades raras a veces se denominan "enfermedades huérfanas». El término es apropiado por varias razones. En primer lugar, «huérfano» se aplica a los niños, y sucede que los recién nacidos, los bebés y los niños corren el mayor riesgo de contraer las enfermedades raras más devastadoras. En segundo lugar, el concepto de "enfermedad huérfana" implica una falta de administración.

Este número extraordinario está destinado a comprender mejor la fisiopatología, el tratamiento y el seguimiento de los pacientes con algunas enfermedades raras del corazón, a la luz de los conocimientos actuales.

Queremos expresar nuestro agradecimiento sincero a los autores que han contribuido gentilmente a esta edición, por todo su esfuerzo y el tiempo invertido.

\section{Correspondencia:}

*Darío Echeverri

E-mail: decheverri@cardioinfantil.org
Fecha de recepción: 05-03-2020

Fecha de aceptación: 12-03-2020 DOI: 10.24875/RCCAR.M21000034
Disponible en internet: 28-06-2021 Rev Colomb Cardiol. 2021;28(Supl 2):1 www.rccardiologia.com 0120-5633 / @ 2020 Sociedad Colombiana de Cardiología y Cirugía Cardiovascular. Publicado por Permanyer. Este es un artículo open access bajo la licencia CC BY-NC-ND (http://creativecommons.org/licenses/by-nc-nd/4.0/). 